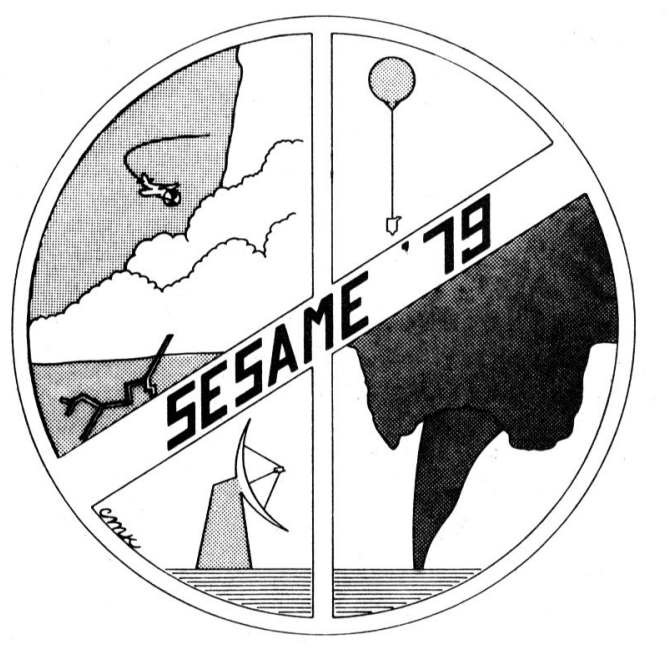

SESAME NEWYS

No. 1

November 1979

A series of informative contributions concerning the SESAME project and its 1979 field program, supported by the National Oceanic and Atmospheric Administration, the National Aeronautics and Space Administration, the National Science Foundation, and others. Prospective contributions should be sent to Professor Frederick Sanders, Department of Meteorology, Massachusetts Institute of Technology, Cambridge, Mass. 02139.

\title{
NASA's Participation in the AVE-SESAME '79 Program
}

\author{
Kelly Hill, Gregory S. Wilson, ${ }^{1}$ and Robert E. Turner \\ Atmospheric Sciences Division, Space Sciences Laboratory \\ National Aeronautics and Space Administration \\ Marshall Space Flight Center, Ala. 35812
}

\begin{abstract}
NASA's Marshall Space Flight Center (MSFC) participated with its AVE (Atmospheric Variability Experiment) in a large interagency mesoscale and severe storms experiment identified herein as AVE-SESAME'79 (Atmospheric Variability Experiment-Severe Environmental Storms and Mesoscale Experiment 1979). A primary objective of NASA was to support an effort to acquire carefully edited sets of rawinsonde data during selected severe weather events for use in correlative and diagnostic studies with satellite and radar data obtained at approximately the same times. Data were acquired during six individual $24 \mathrm{~h}$ experiments on both the regional and storm scales over a network in the central United States that utilized approximately 20 supplemental rawinsonde sites meshed among 23 standard National Weather Service sites. Included among the six experiments are data obtained between 1200 GMT on 10 April and 1200 GMT on 11 April, encompassing the formation and development period for the tornado-producing systems that devastated Wichita Falls, Tex., and other sections of Oklahoma and Texas. The other dates for which data sets are available are 19-20 and 25-26 April, 9-10 and 20-21 May, and 7-8 June 1979.
\end{abstract}

\section{Introduction and background}

Severe storms, to a large extent, appear to be initiated or controlled by mesoscale dynamics. However, the concentration of major research in atmospheric sciences has, in the past, focused on the large and small ends of

${ }^{1}$ USRA Visiting Scientist. the atmospheric scales of motion, and has left a gap in the understanding of phenomena associated with mesoscale systems. It is widely acknowledged that our lack of knowledge about the structure and organization of mesoscale systems forms one of the greatest obstacles to developing a general understanding of severe local storms and their parameterization for numerical and statistical forecast models.

To learn more about the structure and dynamics of mesoscale systems, NASA, in cooperation with NOAA and other government agencies, participated in a field experiment identified herein as AVE-SESAME '79 (Atmospheric Variability Experiment-Severe Environmental Storms and Mesoscale Experiment). One of NASA's primary objectives in this program was to support a continuing effort to acquire carefully edited sets of rawinsonde data during six selected severe weather events for use in correlative and diagnostic studies with satellite and radar data measured at approximately the same times (Kreins, 1979). This activity represents a continuation of a series of similar experiments, conducted during the years 1964-78, under NASA's Atmospheric Variability Experiment (AVE) Program (Hill and Turner, 1977).

A brief description of each of these experiments, including the AVE-SESAME' 79 data, is given in Table 1. Figure 1 shows the GOES-East enhanced 
TABle 1. Summary of NASA's AVE, AVSSE,* and AVE-SESAME '79 experiments.

\begin{tabular}{|c|c|c|c|c|}
\hline Experiment & Dates & Observation times, GMT & Experiment size and location & $\begin{array}{c}\text { Significant meteorological } \\
\text { conditions }\end{array}$ \\
\hline
\end{tabular}

AVE 1

19-23 Feb. 1964

19

20

21

22

23

AVE 2

11-12 May 1974

$12,15,18,21$

$00,03,06,09,12$

$00,03,06,09,12,15,18,21$

$00,03,06,09,12,15,18,21$

$00,03,06,09,12,15,18,21$

$00,03,06,09,12,15,18,21$

00

Thirty-one rawinsonde stations were used in 18 states stretching from Nebraska, Kansas, Oklahoma, and Texas eastward to the middle Atlantic and southeastern states.

Fifty-four rawinsonde stations encompassing most of the states east of $105^{\circ} \mathrm{W}$ in the United States.

$00,06,12,15,18,21$

$00,06,12$

6-7 Feb 1975

7

AVE 4

24-25 April 1975

24

25

$00,06,12,15,18,21$

$00,06,12$,

\section{7-28 April 1975}

27

28

$12,15,18,21$

$00,03,12$

Twenty-four rawinsonde stations were used that covered parts of 13 southwestern and southern states from New Mexico and Colorado eastward to Tennessee and Georgia.

AVSSE 2

$\begin{array}{rr}6-7 & \text { May } 1975 \\ 6 & \\ 7 & \end{array}$

$12,15,18,21$

$12,15,18$,
$00,03,12$

Twenty-three rawinsonde stations covering almost the same area as AVSSE 1.

Twenty-three rawinsonde stations in 15 of the north-central states were used from Montana, Wyoming, and Colorado eastward to Michigan, Ohio, Tennessee, and Alabama.
Surface cyclonic system developed over the Gulf of Mexico and moved into the northeastern states accompanied by strong upperlevel thermal gradients and winds.

Complex frontal and upperlevel system moved through the Missouri Valley and Midwest and interacted with an active cut-off low over the lower Mississippi Valley. Strong convective activity and horizontal temperature gradients were present.

A strong polar air mass moved through the Mississippi and Ohio Valleys accompanied by snowfall in the cold air and convective activity near the frontal system.

A major tornado outbreak occurred from Missouri and Oklahoma eastward into Tennessee and northern Alabama.

Tornadoes and other severe storms occurred primarily in Nebraska and Oklahoma in conjunction with a cold front running through the central plains states and a developing upper-level low over South Dakota.

A major tornado occurred in Omaha, Nebr. Other tornado and funnel activity developed from Oklahoma and Arkansas northward to South Dakota associated with a cold front and dry line.

Tornadoes and other severe storms developed primarily in North and South Dakota associated with a cold front in that region. 
TABLE 1-continued.

\begin{tabular}{cccc}
\hline \hline Experiment $\quad$ Dates $\quad$ Observation times, GMT & Experiment size and lòcation & $\begin{array}{c}\text { Significant meteorological } \\
\text { conditions }\end{array}$
\end{tabular}

\begin{tabular}{ccl}
\hline AVE 6 & $27-28$ May 1977 & \\
27 & $00,12,15,18,21$ \\
28 & $00,03,12$
\end{tabular}

AVE 7

$\begin{array}{rr}2-3 & \text { May } 1978 \\ 2 & \\ 3 & \end{array}$

$00,12,15,18,21$

$00,03,12$

AVE-SESAME 1 10-11 Apr 1979

$\begin{array}{ll}10 & 12,15,18,21 \\ 11 & 00,03,06,09,12\end{array}$

AVE-SESAME 2 19-20 Apr 1979

$\begin{array}{ll}19 & 12,15,18,21 \\ 20 & 00,03,06,09,12\end{array}$

AVE-SESAME 3 25-26 Apr 1979

$\begin{array}{ll}25 & 12,15,18,11 \\ 26 & 00,03,06,09,12\end{array}$

ÄVE-SESAME 4 9-10 May 1979

9
10

\author{
$12,15,18,21$ \\ $00,03,06,09,12$ \\ (supplemental sites
} at other times)

AVE-SESAME 5 20-21 May 1979

$\begin{array}{ll}20 & 12,15,18,21 \\ 21 & 00,03,06,09,12 \\ \text { (supplemental sites } & \text { at other times) }\end{array}$

AVE-SESAME $6 \quad 7-8$ June 1979

$\begin{array}{cl}7 & 12,15,18,21 \\ 8 & 00,03,06,09,12 \\ \text { (supplemental sites } & \text { at other times) }\end{array}$

Twenty-two rawinsonde stations covering an area from South Dakota to Texas and eastward to Illinois and Alabama.

Twenty-four rawinsonde stations covering an area approximately the same as AVE 6.

(See Fig. 3a)

(See Fig. 3a)

(See Fig. 3a)

(See Fig. 3b)

(See Fig. 3b)

(See Fig. 3b)
Severe thunderstorms occurred in Missouri, Tennessee, and Oklahoma.

Severe thunderstorms, tornadoes, hail, snow, and flooding occurred over Texas and Louisiana in association with strong disturbances aloft over the southern Rockies.

Major tornado outbreak in Texas and Oklahoma and general thunderstorm activity over the midwestern United States occurred in conjunction with a strong cyclone centered over eastern Colorado.

A tornado outbreak stretching from North Dakota to Texas and major flooding in southeast Texas occurred in advance of a cold front located along the eastern slopes of the Rocky Mountains.

Since the thunderstorms occurred in Missouri and Illinois along a cold front in the midwestern United States, general thunderstorm activity was located in the Mississippi River Valley and eastern plains States.

Thunderstorms stretched from the Great Lakes southward into Texas along an advancing cold front.

Tornadoes and hail occurred in Texas, Oklahoma, and Kansas.

Thunderstorms occurred from the Appalachians westward into Oklahoma and Texas along a cold front. Several tornadoes occurred in west Texas.

Widespread thunderstorm activity, causing locally heavy rains, occurred from the Great Lakes into Texas in association with a cold front located in the midwestern United States.

* Atmosphere Variability and Severe Storms Experiment (same as AVE measurements). 


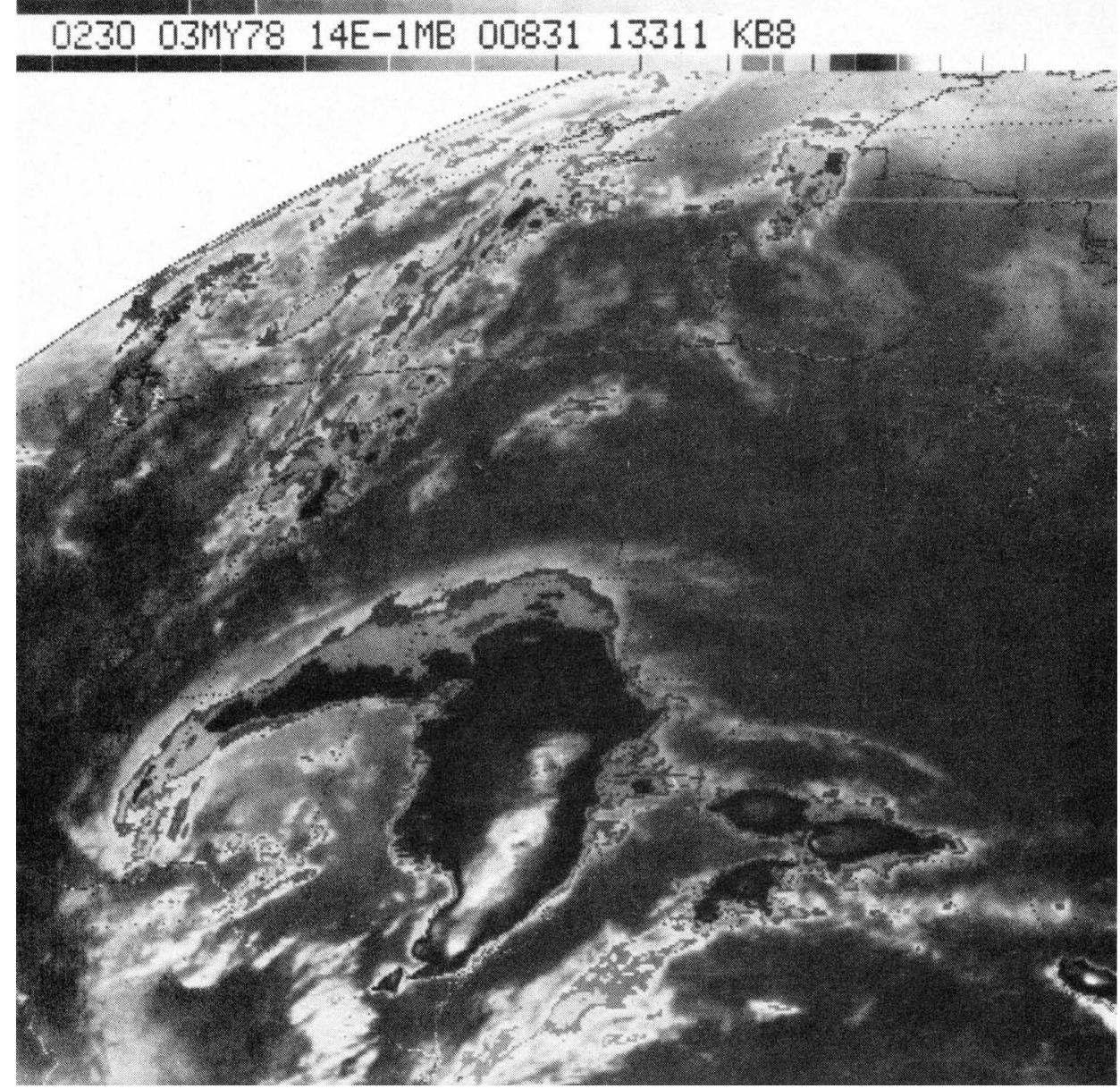

FIG. 1. GOES-East enhanced infrared satellite imagery for 0230 GMT on 3 May 1978.

infrared satellite imagery for 0230 GMT on 3 May 1978, a time period during AVE 7. The concurrent analysis of Manually Digitized Radar data is shown in Fig. 2 for 0235 GMT on 3 May. The squall line and precipitation shield in Texas and Oklahoma seen in Figs. 1 and 2 represents only one of many deep and intense synoptic and mesoscale weather disturbances captured during past Atmospheric Variability Experiments.

\section{AVE-SESAME '79 program}

The new AVE-SESAME '79 data contain higher spatial and/or temporal resolution than most prior AVE data sets and will be used to examine the fundamental mesosynoptic processes responsible for the formation and development of severe convective activity associated with phenomena such as tornadoes, damaging winds, hail, floods, turbulence, etc., that affect property and personal safety. A second objective is to compile a data set for investigating atmospheric variability and associated severe storm development with emphasis on the determination of mechanisms for the formation and prediction of severe storms.
Atmospheric circulation systems on the regional. meso, local, and convective scales involve very complex physical processes, including important contributions from the underlying geography, intense heat release, and nonlinear interactions between the larger and smaller scales. Because the important physical processes, scientific methods/techniques, and the state of knowledge are all scale-dependent, the AVE-SESAME '79 experiments were conducted using two different observational networks. Three of the six experiments were conducted in April within a regional-scale network and three in the May-June period within the stormscale network.

The regional-scale experiments (see network in Fig. 3a) consisted of $24 \mathrm{~h}$ periods of observation involving 23 National Weather Service (NWS) rawinsonde sites and 17 supplemental rawinsonde sites taking measurements at $3 \mathrm{~h}$ intervals during three severe weather outbreak days in April. Rapid scan visual and infrared imagery was acquired by GOES satellites, and TIROS-N and NIMBUS-G data were also obtained during certain periods of these experiments. 


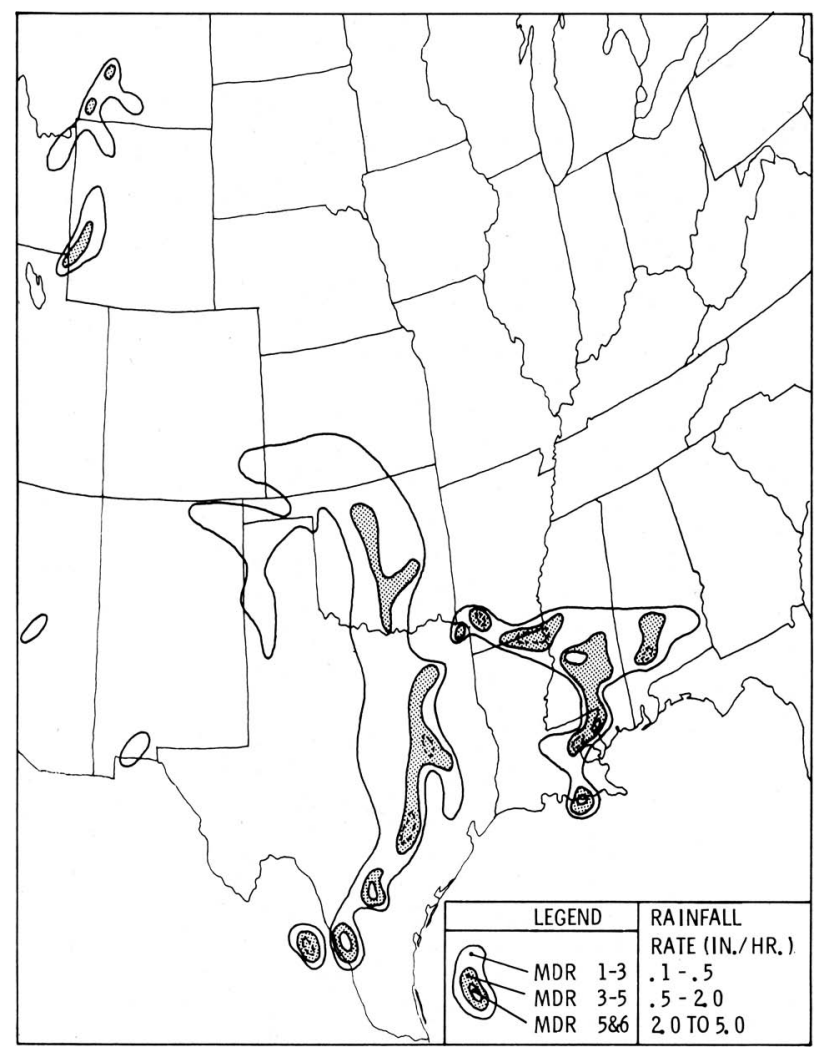

FIG. 2. Analysis of Manually Digitized Radar Data for 0235 GMT on 3 May 1978.

Special conventional and Doppler radar and aircraft measurements were obtained during thunderstorm development periods from stations located in the experiment area. Note that special rawinsonde data were acquired during the formation, development, and dissipation stages of the major tornado-producing systems that devastated Wichita Falls, Tex., and areas in Oklahoma and Texas on 10-11 April 1979.

The enhanced infrared satellite imagery at 2330 GMT on 10 April (Fig. 4) shows the cold cloud tops over Texas and Oklahoma that less than $1 \mathrm{~h}$ later were associated with the tornadic thunderstorms responsible for the Wichita Falls, Tex., tornado. A small and moderately cold cloud line located in west central Texas (running from southwest to northeast) eventually developed into a long line of severe thunderstorms that moved eastward into central Texas. Some of the tremendous number of severe weather reports that occurred during the $24 \mathrm{~h}$ period between $1200 \mathrm{GMT}$ on 10 April and 1200 GMT on 11 April 1979 during AVE-SESAME 1 are plotted in Fig. 5.

The storm-scale experiments consisted of three $24 \mathrm{~h}$ periods of observations involving approximately 23 National Weather Service rawinsonde sites (some as regional scale) taking measurements at $3 \mathrm{~h}$ intervals, and about 20 supplemental rawinsonde sites taking measurements at 1.5 and/or $3 \mathrm{~h}$ intervals during severe weather events closer to Oklahoma (see Fig. 3b). Special satellite, radar, aircraft, surface, and conven-
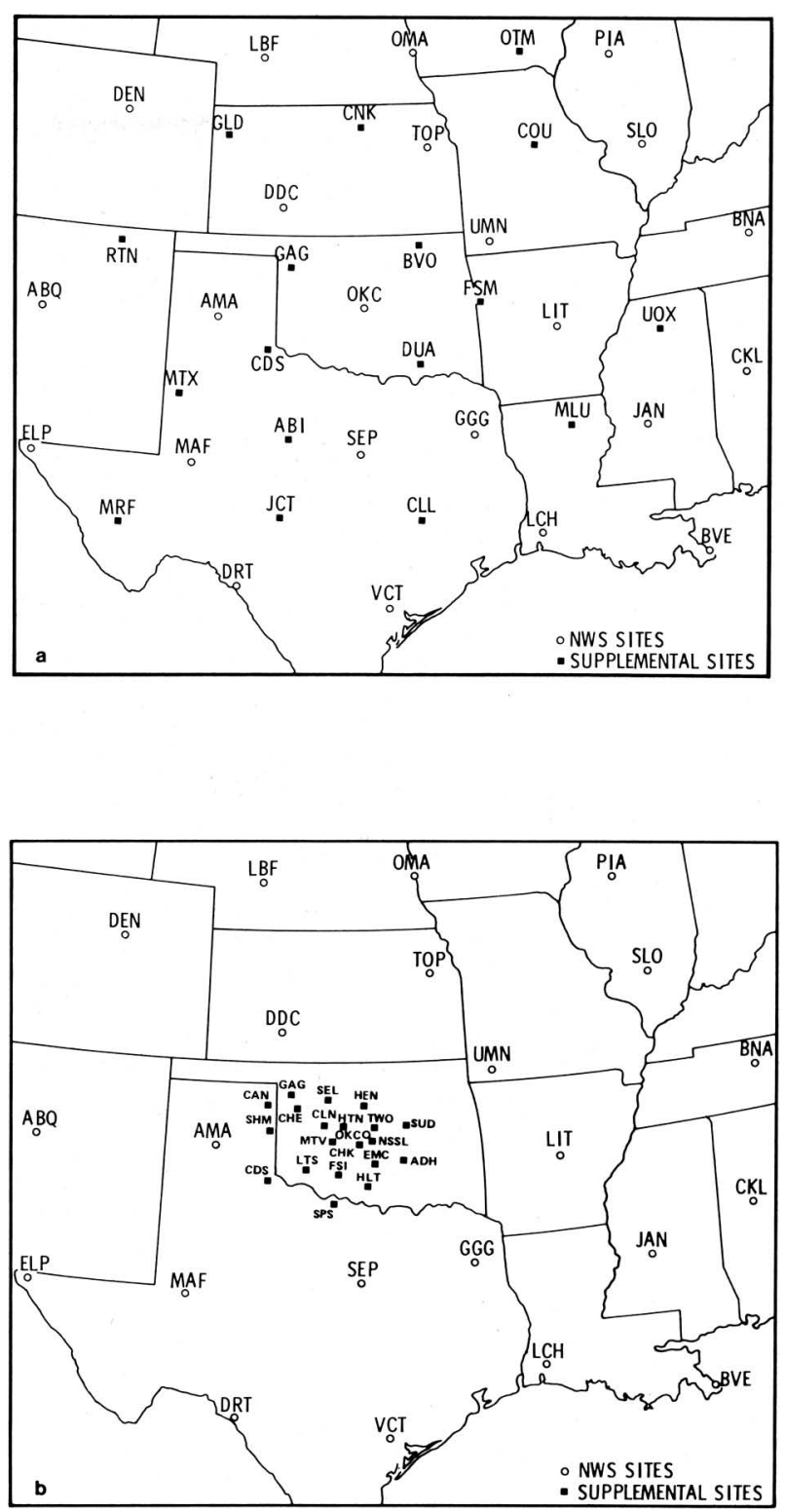

FIG. 3. Rawinsonde station networks: (a) AVE-SESAME '79 regional-scale and (b) storm-scale.

tional measurements were acquired as in the regionalscale experiments but the primary measurement area of interest was focused on Oklahoma.

All rawinsonde data will be reduced by the NASAAVE technique, which will include a quick-look assessment and documentation of each experiment (Fuelberg, 1974). This data reduction technique is designed to extract every meaningful and accurate measurement taken during each rawinsonde flight. Analysis of the temporal and spatial continuity of the individual soundings insures a final data set with internal consistency. Each data set obtained from the six experiments will be provided upon request, by NASA's Marshall Space Flight Center, to all investigators and the scientific community in hard copy form and/or on magnetic tape. 


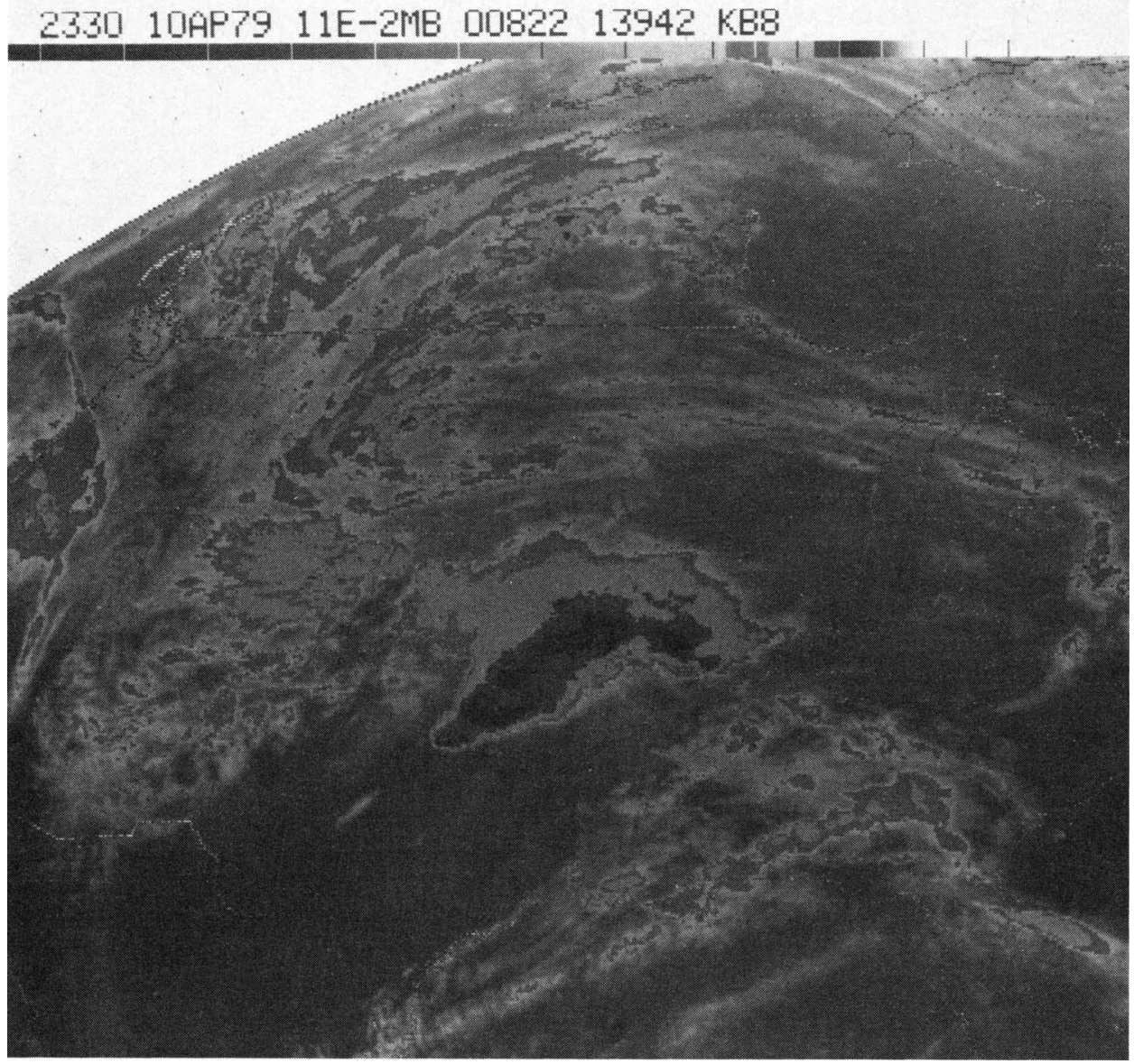

FIG. 4. GOES-East enhanced infrared satellite imagery for 2330 GMT on 10 April 1979.

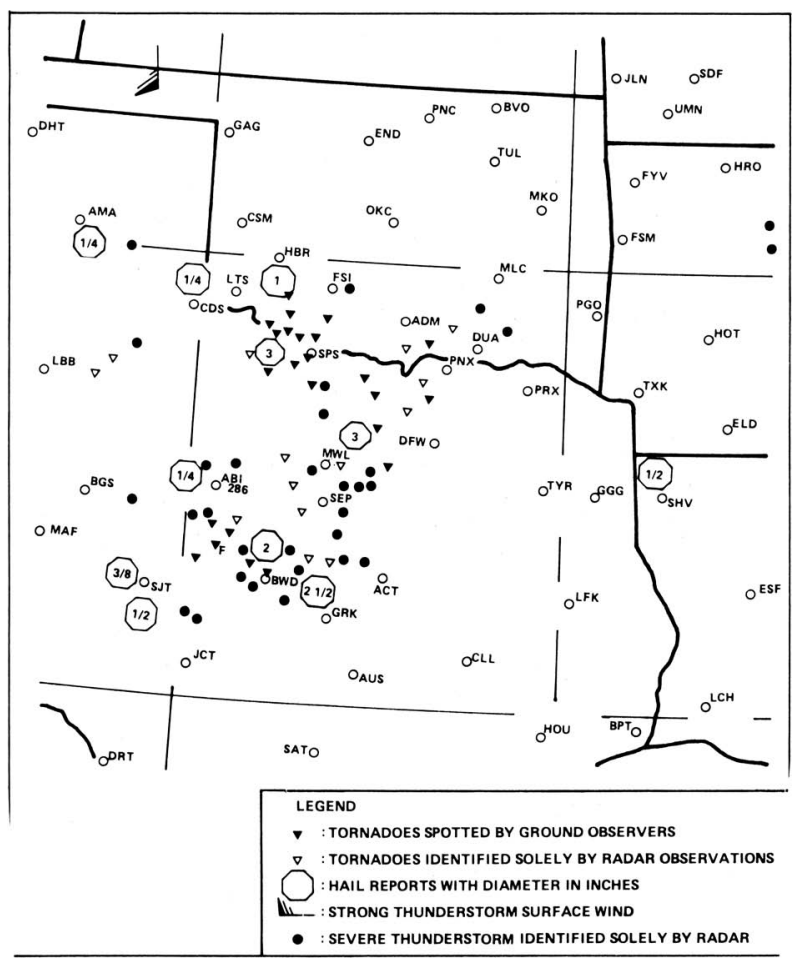

\section{Potential research areas}

The number of potential scientific studies that could be conducted using the data available from these experiments is high. Some possibilities are:

1) Examine conditions that lead to the severe and unusual weather events throughout the experiment day. This would include diagnostically calculated and numerically predicted vertical motion (lifting mechanisms), kinematic parameters, convective instability, air structure, etc.

2) Perform studies of budgets of energy (transformations included), moisture, and vorticity to determine the source of energy for the storms and mechanisms responsible for the release of the latent energy.

3) Relate satellite observations to results from various analyses to determine what can be learned from satellite data about the conditions established from $3 \mathrm{~h}$ and $1.5 \mathrm{~h}$ rawinsonde data.

FIG. 5. Severe weather reports that occurred during the $24 \mathrm{~h}$ period between $1200 \mathrm{GMT}$ on 10 April and 1200 GMT on 11 April 1979 in the south-central United States. 
4) Investigate the role of the jet stream in the formation of convective activity.

5) Develop improved storm forecast capability through the development of models of severe storms and their environment that use space technology and conventional ground-based data sources.

6) Perform correlative analyses of the satellite and ground measurements to determine the critical atmospheric variables or storm severity indicators that may be required for future sensor system developments.

These are only a few of the possibilities. Research results from the utilization of these AVE-SESAME'79 data sets will be documented and made available to the scientific and application user communities in studies relating to the understanding and knowledge of severe weather. Reports involving analysis of other AVE and AVSSE (Atmospheric Variability and Severe Storms Experiment) data sets are currently available from NASA.

Acknowledgments. Participation by MSFC in the AVESESAME ' 79 program was supported by the Severe Storms and Local Weather Research Program (James Dodge,
Manager) of NASA Headquarters' Office of Space and Terrestrial Applications. The authors wish to thank Mr. Don Foster and Mr. Ron Reap of the National Weather Service's Techniques Development Laboratory for providing the Manually Digitized Radar Data, and Mr. Ken Koch of the National Weather Service Forecast Office in Atlanta, Ga., and Dr. A. H. Thompson of Texas A \& M University, for supplying satellite data. The severe storm reports of 10-11 April 1979 were provided by Mr. Jim Lynch through an unpublished summary of the Severe Storm Intercept Program sponsored by the Department of Meteorology, Texas A \& M University. Dr. Henry Fuelberg of St. Louis University provided synoptic summaries for the six AVE-SESAME experiments. Special thanks are due to Dr. W. W. Vaughan for his comments and review of this article.

\section{References}

Fuelberg, H. E., 1974: Reduction and error analysis of the AVE II pilot experiment data. NASA CR-120496, NASA, Marshall Space Flight Center, Ala.

Hill, K., and R. E. Turner, 1977: NASA's Atmospheric Variability Experiment (AVE). Bull. Am. Meteorol. Soc., 58, 170-172.

Kreins, E. R., 1979: Fourth National Aeronautics and Space Administration weather and climate program science review. NASA Conf. Publ. 2076, NASA, Goddard Space Flight Center, Md. 